\title{
Large ventricular aneurysms occurring after myocardial infarction
}

\author{
B. LETAC, G. LEROUX, A. CRIBIER, AND R. SOYER \\ From Service des Soins Intensifs Cardiologiques et des Explorations Hémodynamiques Cardiovasculaires, \\ Centre Hospitalier Universitaire de Rouen, Hôpital Charles-Nicolle, Rouen, France
}

SUMMARY We have studied 33 patients with a large ventricular aneurysm complicating an anterior myocardial infarction. The features of myocardial infarction progressing towards an aneurysm were no previous history of coronary disease, severe infarction as shown by the severity of pain and the presence of pericardial rub and heart failure, and large increase in serum levels of cardiac enzymes.

A large aneurysm usually follows a large infarction resulting from the total or partial occlusion of the left anterior descending artery, which is involved alone in about half the patients and is associated with lesions of the circumflex and right coronary arteries in the other half. In most cases, standard radiography showed an abnormal cardiac configuration, but in 7 patients $(21 \%)$ there was no radiological evidence of aneurysm. ST segment elevation (mean $2.7 \mathrm{~mm}$ ) was reported in all subjects but one.

Heart failure was present in most patients and was an indication for surgical treatment in one-third of the patients.

A large aneurysm was not a contraindication to operation even when at angiography the aneurysm seemed to occupy almost all the left ventricle. Twenty-one patients were operated upon for resection of the aneurysm with a mortality rate of 14 per cent.

Ventricular aneurysm, a common complication of myocardial infarction, is now readily diagnosed by angiocardiography, and its high incidence is confirmed by left ventriculography carried out when coronary angiography is performed. The consequences of ventricular aneurysm may be so severe that surgical treatment may be indicated.

Thirty-three patients, all with a large ventricular aneurysm complicating an anterior myocardial infarction, were included in this study. The aneurysm was surgically resected in 21 of them.

\section{Subjects and methods}

The 33 patients included 27 men and 6 women, of mean age 58 years (range 32 to 76 years).

Angiography showed a sac protruding from the remaining left ventricular contour during both systole and diastole in all the patients included in this series. The presence of a permanent deformity of the ventricular cavity, even during diastole, was the main criterion for the selection of patients. Only those patients with large aneurysms on ventri-

Received for publication 9 June 1977 culography, that is at least half the total size of left ventricular cavity, were included in the study.

Haemodynamic and angiographic studies were carried out in all patients except one examined at necropsy. Single plane left ventriculography, at $\mathbf{4 8}$ frames per second in the right anterior oblique position, was performed in 29 patients by direct injection into the left ventricle, and in 3 patients by injection into the pulmonary artery. In 1 patient, who had the largest aneurysm, 2 injections were necessary, the first with the tip of the catheter placed within the cavity of the aneurysm and the second after withdrawing the catheter into the outflow tract. Coronary arteriography was done in 30 patients.

As 20 of the 33 patients were referred to our cardiology department during the acute stage of myocardial infarction, they could be followed until the diagnosis of aneurysm was made and confirmed by angiography, and thus the natural history of the disease could be reviewed from the initial infarction to the development of the aneurysm. The data relating to the acute stage of these infarctions progressing to aneurysm were compared with those from a series of 200 successive acute myocardial infarctions seen in our unit (Mauviard, 1975). 


\section{Results}

\section{HISTORY}

Clinical symptoms of coronary heart disease before the myocardial infarct occurred in only 7 of 33 patients $(21 \%)$ in whom aneurysm developed. Only 5 had had angina pectoris of relatively recent onset (15\% compared with $50 \%$ in the series of 200 myocardial infarctions). The other 2 had had no angina but had already had a myocardial infarct (6\% compared with $16 \%$ in the series of 200 patients). In 10 patients there was a history of hypertension (30\% compared with $38 \%$ in the series of 200 patients), which was moderate in 8 and severe (diastolic blood pressure over 120 $\mathrm{mmHg}$ ) in 2.

\section{FEATURES OF MYOCARDIAL INFARCTION} CONDUCIVE TO ANEURYSM FORMATION

A comparison was made between the series of 200 myocardial infarctions and the 20 aneurysm patients seen in the coronary care unit during the acute stage of infarction and the following characteristics distinguished the aneurysm patients. In most of them the initial pain was of long duration, lasting on average for 21 hours compared with a mean duration of 11 hours in the series of 200 cases. The pain persisted for more than 12 hours in 13 of the 20 cases ( $65 \%$ of cases compared with $34 \%$ in the series of 200 patients). A pericardial rub could be heard in 12 of the 20 patients $(60 \%$ compared with $7.5 \%$ in the 200 patients), and in 8 patients was loud and lasted for 24 hours or more. Body temperature was very similar in both groups. The mean maximal temperature was $38.8^{\circ} \mathrm{C}$ in the 20 patients with myocardial infarction leading to aneurysm, and $38.7^{\circ} \mathrm{C}$ in the series of 200 cases. Clinical evidence of heart failure was found in 15 of 20 patients $(75 \%$ compared with $57 \%$ in the series of 200 cases) and heart failure was severe in 8. Serum levels of myocardial enzymes were in general very high. Creatine kinase values were, on average, 11 times higher than normal (mean value of 590 units/1 compared with an upper limit of normal of 50 units $/ 1$, and a mean of 365 units $/ 1$ in the series of 200 cases). Mean $\alpha$-HBD levels were 6 times higher than normal, i.e. mean of 1230 units/1 (707 units/1 in the series of 200 cases).

As is customary in our cardiology department, the 20 patients admitted under our care at the time of infarction were up early (first sitting in an armchair from the second to the fourth day, then walking from the eighth to the tenth day, according to the severity of their heart condition), but as most of these patients had had a severe myocardial infarct, they were usually mobilised at a later date than the others, except for one who required urgent operation on the twentieth day because of severe cardiac failure. The 13 remaining patients, who were not admitted to our department during the initial stage, had the appropriate amount of rest except for 5 in whom the infarct was ignored.

Anticoagulant treatment was given from the onset of infarction to the 20 patients in hospital and to 8 of the 13 others. The 5 patients who were not given anticoagulants were those who were not kept at rest during the initial stage as the infarction was not recognised. None of the patients had received corticosteroid treatment (Bulkley and Roberts, 1974). The Dressler syndrome was not observed in any of the patients (Bounhoure et al., 1973).

\section{INTERVAL BETWEEN INFARCTION AND} DETECTION OF VENTRICULAR ANEURYSM The interval between myocardial necrosis and the recognition of an aneurysm in these 33 patients ranged from a few days to several years. The diagnosis of aneurysm was suggested in $10(50 \%)$ of the 20 patients followed up from the initial stage before the 8th day by the presence of a very wide apical impulse. In one of these the diagnosis was confirmed on the 15th day by haemodynamic study done as an emergency on account of severe heart failure. In the 23 remaining patients the time interval between the causal infarction and the discovery of aneurysm averaged 24 months (ranging from 1 month in 3 patients to 13 years in 2 patients).

\section{CLINICAL DATA AT STAGE OF ESTABLISHED} VENTRICULAR ANEURYSM

Clinical data were available in all 33 cases in the study.

\section{Clinical examination}

Palpation of the praecordial area suggested a ventricular aneurysm in 21 out of 33 patients $(64 \%)$. A clear double impulse was observed in 9 and a sensation of spread from the apex in 12. This was specific in that a sensation of lift could be felt, with its maximal intensity higher and more medial than in other patients with commoner causes of cardiac enlargement. On auscultation a gallop rhythm was present in most patients (29 out of 33, $88 \%$ ); this was a summation gallop in 5 , protodiastolic in 6 , and presystolic in the remaining 18 patients. A systolic murmur was present in 7 (21\%).

\section{Electrocardiogram}

The site of the aneurysm could be identified by the presence of broad and deep $Q$ or $Q S$ waves, sequelae of the infarction responsible for the aneurysm. The site was anteroseptal in 11 patients 
(33\%), extensive anterior in $17(51 \%)$, and septal in $5(15 \%)$. Thirty patients were in sinus rhythm, and 3 were in atrial fibrillation. The QRS axis was normal (average $+70^{\circ}$ ) in only 8 patients and in 3 patients it was between $+90^{\circ}$ and $+270^{\circ}$; in the 21 others there was left axis deviation (average $-60^{\circ}$ ) with $\mathrm{T}$ axis opposite the QRS axis and a $+90^{\circ}$ gradient. In the other patient complete left bundle-branch block appeared between the initial infarction and the discovery of the aneurysm.

ST segment elevation was present in all except one patient in whom the ST segment was not raised despite the presence of a very large ventricular aneurysm. The mean value for ST segment elevation (excluding the last case) was $2.7 \mathrm{~mm}$ (range $1 \mathrm{~mm}$ to $10 \mathrm{~mm}$ ). No relation was found between the height of the ST segment and the size of the aneurysm.

\section{Standard radiography}

In most patients, standard frontal radiography showed an abnormal cardiac contour, but in 7 patients (21\%) the cardiac contour and heart size were normal. In 22 patients (67\%), there was obvious cardiac enlargement, which was considerable in 16 $(48 \%)$. In $15(45 \%)$, the cardiac contour was distinctly abnormal and distorted by a break in the outline or by an irregularity of the lower left border of the heart. Calcification was seen in one patient with a very large aneurysm which distorted the lower left border. This aneurysm followed an infarction which had occurred 13 years previously and was discovered during an attack of ventricular tachycardia in a 76-year-old patient.

\section{Haemodynamic data}

Haemodynamic data were obtained in 32 of the 33 patients. The mean value for left ventricular enddiastolic pressure (LVEDP) was $23 \mathrm{mmHg}$. LVEDP was normal in $5(16 \%), 12$ to $20 \mathrm{mmHg}$ in 9,21 to $30 \mathrm{mmHg}$ in 12, and over $30 \mathrm{mmHg}$ in 6 others. All patients with LVEDP equal to or above $20 \mathrm{mmHg}$ had very large aneurysms, but 4 of the largest aneurysms were in patients with a normal LVEDP. Measurements of the cardiac output by the Fick method or by a dilution technique were made in only 8 patients. The mean value was $1.91 / \mathrm{min}$ per $\mathrm{m}^{2}$, with extremes ranging from 1.2 with LVEDP $34 \mathrm{mmHg}$ to $2 \cdot 8$ with LVEDP $12 \mathrm{mmHg}$. In 2 other patients, the arteriovenous oxygen differences were $6 \cdot 2$ and $7 \cdot 6$ volumes, indicative of an appreciable decrease in output.

\section{Angiocardiographic data}

It is possible, but difficult, to assess the volume of the aneurysm accurately. A rough assessment may be made by comparing the area of the angiographic ventricular silhouette either with that of a normal ventricle or by reference to the remaining sound myocardium. All the aneurysms in this series of patients were large, with angiocardiographic volume more than half that of the whole left ventricular cavity; in 23 patients the volume of the aneurysm was about two-thirds that of the left ventricle. There was conspicuous hypokinesis of the remaining unaffected myocardium with overt dilatation of the ventricular cavity in 8 patients $(25 \%)$. Mitral regurgitation was found in 11 of the 29 patients $(38 \%)$ in whom left ventriculography was undertaken, but was usually mild. Of the 7 patients with a systolic murmur, 6 had mitral regurgitation as shown by left ventriculography, whereas the 5 others had mitral regurgitation with no systolic murmur.

In one patient, the heart at necropsy could be compared with the left ventriculogram. The aneurysm was anterior and fairly large. When the heart was opened, the aneurysm cavity was found to be partly filled by necrotic tissue with a core of the consistency of syrup surrounded by several layers over 3 or $4 \mathrm{~cm}$ thick. Calcification was present to a depth of 2 to 3 $\mathrm{mm}$ round the periphery.

\section{Coronary angiography}

This was undertaken at the same time as left ventriculography in 30 patients. The left anterior descending artery was the site of a major stenosis $(\geqslant 90 \%)$ in all patients. It was completely obstructed in 19, and in the 11 remaining patients the stenosis was approximately 90 to 95 per cent and beyond it the artery was visible but was thin and irregular and of a very small calibre, though continuing almost to the apex. In 15 patients $(50 \%)$ the left anterior descending artery alone was affected, the right coronary and circumflex arteries being normal. In 5 patients $(17 \%)$ the major lesion of the left anterior descending was associated with a stenosis $(\geqslant 70 \%)$ of one of the other arteries, circumflex or right coronary. Finally, in 10 patients $(33 \%)$ there were also associated lesions (stenosis $\geqslant 70 \%$ ) of both circumflex and right coronary arteries. There was no relation between the various types of coronary lesions and the size of the aneurysm.

Severe coronary lesions were present in all 3 arteries in 5 of the 8 patients with overt hypokinesis of the remaining myocardium, and involved two arteries (left anterior descending and right) in 2 patients; no coronary arteriogram was obtained in the eighth patient. In 5 patients with a history of angina, multiple coronary lesions were present in 3 and stenosis of the left anterior descending artery only in 2 . 


\section{Complications}

There were overt symptoms of heart failure of varying severity in 19 patients (58\%). In $12(36 \%)$ failure was biventricular and severe: one of these patients died.

Various arrhythmias were reported in 11 patients $(33 \%)$. Different types of arrhythmia were sometime seen in the same patient: they included atrial fibrillation in 3 , supraventricular tachycardia in 2 , frequent ventricular extrasystoles (rate $\geqslant 8 / \mathrm{min}$ ) in 6 , and ventricular tachycardia in 6 . In 2 patients ventricular tachycardia was followed by irreversible ventricular fibrillation.

No systemic emboli was seen, but all patients received efficient anticoagulant therapy. Transient hemiparesis was, however, observed in 2 patients during catheterisation and was probably the result of a clot dislodged from the aneurysmal sac.

\section{PROGRESS OF ESTABLISHED VENTRICULAR ANEURYSM}

Of the 33 patients studied, $21(64 \%)$ were operated on. Surgical intervention was recommended in most cases because of symptoms of severe heart failure or arrhythmias. Major heart failure resistant to digitalis and diuretic treatment was the main reason for operation in 10 patients. In 4 patients the degree of cardiac failure was moderate but arrhythmias which were poorly tolerated (supraventricular tachycardia in 1 case) or threatening (numerous ventricular extrasystoles or episodes of ventricular tachycardia in 3 cases) were also present. In 6 other patients in whom heart failure was moderate and exercise tolerance relatively good, it was the large volume of the aneurysm which led to operation. Finally, in one patient with disabling angina, the main reason for operation was to perform a coronary artery bypass at the same time as resection of the aneurysm. In 7 patients resection of the aneurysm was combined with a coronary artery bypass procedure. In the other 14 patients, aneurysmectomy was performed alone.

There were two surgical deaths, one within hours of operation from low cardiac output, the other sudden on the third day. A third death occurred two months after operation and was the result of low cardiac output. Thus, of the 21 patients who underwent operation, 3 died, a mortality of 14 per cent. All the other 18 patients who had operations showed considerable improvement, with disappearance of heart failure and no recurrence of arrhythmia. However, 2 went back into severe heart failure during the following months and eventually died within 18 months of operation. The 16 other patients are in fairly good health with a follow-up period of 2 to 6 years, though half of them have symptoms of left ventricular failure.

Of the 12 patients who were not operated on, 4 died $(33 \%): 3$ of these patients died within days or weeks of diagnosis, 2 from ventricular tachycardia leading to irreversible ventricular fibrillation and 1 in severe heart failure; the other patient died suddenly one year later. In 2 of these 4 patients, operation was not advised because of their good clinical condition. On the basis of 2 to 6 years of appraisal, 4 of the 8 remaining unoperated patients have tolerated their aneurysm well, 2 of them remaining on digitalis and diuretics. The other 4 have persisting signs of heart failure but remain fairly well.

\section{Comments}

Only patients with large left ventricular aneurysms clearly distorting the left ventriculographic contour in both systole and diastole were included in this study; for this reason all the aneurysms were anterior. Posterior aneurysms seldom become very large, perhaps because the posterior wall of the left ventricle is supplied by both the right coronary and circumflex arteries, contrasting with the anterior wall which is almost exclusively supplied by the left anterior descending artery. Another possible explanation is that a large posterior aneurysm. would be accompanied by major mitral regurgitation. caused by papillary muscle involvement and would: be incompatible with life (Björk et al., 1967; Tice et al., 1970; Loop et al., 1973).

It should be noted that it is difficult to draw the line between a true ventricular aneurysm and an extended akinetic area; sometimes the division between a large akinetic area and a slightly protruding aneurysm seems arbitrary (Amiel et al., 1973). All 33 patients in this study had ventricular aneurysms as defined by Edwards (1961). According to this definition an aneurysm is present whenever a protrusion of the ventricular wall distorts the normal cardiac outline, but such an anatomical definition is not adequate for angiocardiographic analysis. The anatomical definition of aneurysm and the angiographic one inevitably differ since the former refers only to the exterior aspect of the heart, while the latter refers to the interior, an idea previously suggested by Edwards himself (1961).

The fact that 20 patients have been followed up from the onset of the causal infarction enabled us to trace the natural history of ventricular aneurysm. In general, myocardial infarctions that are likely to progress towards aneurysm have characteristic clinical features. In most patients the causal infarction occurred without a previous history of coronary disease ( 26 of 33 ), as had been observed 
by Himbert and Rochemaure (1967). These infarctions are usually found to be severe as shown by the severity of the clinical illness (pain, pericardial rub, heart failure) and the very high serum levels of cardiac enzymes doubtless resulting from extensive myocardial necrosis. The high incidence of pericardial rub (13 of 19 patients) is characteristic and has previously been reported by Schlichter $e t a l$. (1954) and Delahaye et al. (1973). The development of aneurysm cannot be ascribed to early rising in -hospital as this entails very little physical effort. The time course of the development of aneurysm varies widely, ranging from some davs to several years. In about half the patients who were followed from the initial infarction, the diagnosis was apparent from the 6th to 8th day, which suggests that in the majority of cases, ventricular aneurysms develop very rapidly, though they may not be discovered until they are well advanced, by which time they are already extensive. During the initial phase within the first few days of infarction, it would be probably more accurate to describe an extensive area of akinesia which is stretched by each myocardial contraction, as at that stage there is no actual permanent distortion of the ventricular wall.

Large aneurysms usually follow a large infarction resulting from the occlusion, total or partial, of the left anterior descending artery. In about half the cases this artery alone is involved, and in the remainder there are associated lesions of the circumflex artery and/or the right coronary artery. Thus, in this series, multiple lesions of the coronary arteries were observed much more often than in the series reported by Himbert and Rochemaure (1967) at post-mortem. Impairment of contractility of the remaining myocardium is always (7 cases out of 7) related to damage of all 3 major coronary arteries, but the converse is not true, since relatively good contractility may persist despite diffuse coronary disease; this is frequently observed in patients with coronary heart disease but no ventricular aneurysm. Thus, surgical intervention may be contemplated even with diffuse coronary lesions, provided that contractility of remaining myocardium is satisfactory.

As a rule, aneurysms are relatively easy to recognise on the evidence of clinical, radiological, and electrocardiographic examination. They may, however, be difficult to diagnose in about 20 per cent of patients in whom clinical and radiological signs are absent. These patients are mainly those with apical aneurysms, probably because these enlarge along the long axis of the heart or are concealed by the diaphragm (Baron, 1971; Graber et al., 1972). ST segment elevation was seen in all but one subject in this series. A similar incidence is reported by all authors, but this sign is not constant, being present in 80 to 87 per cent (Cokkinos et al., 1971; Graber et al., 1972). No relation was found between the height of ST segment elevation and the extent of the aneurysm in our series or in others (Delahaye et al., 1973; Cokkinos et al., 1971), in contrast with the experience of Himbert et al. (1966).

In this series, which included large aneurysms only, symptoms of heart failure were present in most cases, and this was the main reason for operation. Haemodynamic investigations showed that the left ventricular end-diastolic pressure was much increased in most cases but normal in 4 despite the presence of a large aneurysm. This observation contrasts with the findings of others who report that aneurysms representing more than 15 per cent of total end-diastolic volume were always accompanied by an increase in end-diastolic pressure (Klein et al., 1967). Arrhythmias were seen in one-third of the patients. The incidence of ventricular tachycardia (18\%) was very similar to that reported by Himbert et al. (1966). Two patients had a supraventricular tachycardia, a type of arrhythmia which has also been reported by Basta et al. (1973).

No systemic embolism was seen in this series, probably because efficient anticoagulant treatment was given. The risk of severe embolism should, however, be taken into account in assessing the prognosis and indications for operation, as this frequently occurs without and even despite anticoagulant treatment (Schlichter et al., 1954; Dubnow et al., 1965; Himbert and Rochemaure, 1967; Mourdjinis et al., 1968; Delahaye et al., 1973).

The mortality rate within 2 months of the operation was 14 per cent, which can be compared with that of Favaloro et al. (1968) (13\%), but is lower than that of Fisher et al. (1974) (19\%), Cooley and Hallman (1968) (20\%), or Graber et al. (1972) $(22 \%)$. More recently, the mortality reported by Cooley and his colleagues was approximately 11 per cent (Standiford et al., 1974). Survivors in our series showed an excellent short-term improvement and the majority showed a good long-term improvement. The results were excellent in those whose clinical condition was relatively good and when operation was undertaken because theaneurysm was large and complications were anticipated. A large aneurysm is not a contraindication to operation even when the angiocardiogram suggests that the aneurysm is replacing almost all the left ventricle, with little or no residual undamaged myocardium. We have observed that the larger the aneurysm the greater the chance of a good surgical result, suggesting that the ability of the heart to maintain its systemic output, in spite of a large aneurysm, proves 
that sufficient healthy myocardium remains. A very large aneurysm indicates gross distension of the infarcted wall or pericardial rupture rather than an extensive loss of ventricular myocardium. Four $(33 \%)$ of 12 non-surgical patients died, but it should be noted that 2 of them died unexpectedly though their clinical state appeared to be good. Taking into account the risk of complications and the satisfactory surgical results, particularly in patients in relatively good health, a liberal approach to surgery seems justified. The main factor determining the surgical result is the existence of healthy remaining myocardium. Myocardial contractility may be assessed from angiographic data (Klein et al., 1967; Crawford et al., 1971; Arthur et al., 1972; Kitamura et al., 1972; Watson et al., 1972; Leaman et al., 1973; Cribier et al., 1976): simple assessment by visual examination of the film gives a rough though generally valuable appraisal. Impaired contractility of the remaining myocardium may indicate coronary lesions involving circumflex and/or right coronary artery in addition to left anterior descending artery, but the converse may not be true, as satisfactory contractility of the remaining myocardium may be seen despite diffuse coronary heart disease. In spite of increased surgical risks and less good results, operation may result in considerable improvement. In the present series 3 patients with diffuse coronary lesions unsuitable for bypass surgery were operated on with satisfactory results and this improvement is still maintained after 3 years.

The authors thank Dr M. A. Rugg Gunn for help in translating this paper.

\section{References}

Amiel, M., Rubet, A., Loire, R., Michaud, P., Mikaeloff, Ph., and Chassignole, C. (1973). Confrontations entre l'angiographie et les données anatomiques per opératoires ou histologiques dans les anévrismes du ventricule gauche. Archives des Maladies du Coeur et des Vaisseaux, 66, 1135-1143.

Arthur, A., Basta, L., and Kioschos, M. (1972). Factors influencing prognosis in left ventricular aneurysmectomy (abstract). Circulation, 45 and 46, Suppl. II, 127.

Baron, M. G. (1971). Postinfarction aneurysm of the left ventricle. Circulation, 43, 762-769.

Basta, L. L., Takeshita, A., Theilen, E. O., and Ehrenhaft, J. L. (1973). Aneurysmectomy in treatment of ventricular and supraventricular tachyarrhythmias in patients with postinfarction and traumatic ventricular aneurysms. American fournal of Cardiology, 32, 693-699.

Björk, L., Cullhed, I., and Hallen, A. (1967). Cineangiocardiographic studies of the left ventricle in patients with angina pectoris. Circulation, 36, 868-877.

Bounhoure, J. P., Bernadet, P., Rumeau, M., Baixas, J., and Galazel, P. (1973). Anévrismes ventriculaires et syndrôme de Dressler Archives des Maladies du Coeur et des Vaisseaux, 66, 1509-1515.
Bulkley, B. H., and Roberts, W. C. (1974). Steroid therapy during acute myocardial infarction: a cause of delayed healing and of ventricular aneurysm. American fournal of Medicine, 56, 244-250.

Cokkinos, D., Hallman, G. L., Cooley, D. A., Zamaolla, O., and Leachman, R. D. (1971). Left ventricular aneurysm: analysis of electrocardiographic features and postresection changes. American Heart fournal, 82, 149-157.

Cooley, D. A., and Hallman, G. L. (1968). Surgical treatment of left ventricular aneurysm: experience with excision of post-infarction lesions in 80 patients. Progress in Cardiovascular Diseases, 11, 222-228.

Crawford, D. W., Barndt, R., Harrison, E. C., Khan, A. W., Haywood, L. J., and Lau, F. Y. K. (1971). Ventricular aneurysm resection: pre-operative estimation of postoperative result (abstract). Circulation, 44, Suppl. II, 155.

Cribier, A., Redonnet, M., and Letac, B. (1976). Quantitative angiographic evaluation of left ventricular aneurysm. In 7th European Congress of Cardiology (Amsterdam), abstract, Book I, p. 248. Ciba-Geigy.

Delahaye, J. P., Touboul, P., Porte, J., Clêment, Ch., Chulliat, J. C., Bons, J. P., and Janin, A. (1973). Problème posé par les anévrismes et dyskinésies ventriculaires aigus. Indications des résections ventriculaires précoces. Archives des Maladies du Coeur et des Vaisseaux, 66, 129-146.

Dubnow, M. H., Burchell, H. B., and Titus, J. L. (1965). Post-infarction ventricular aneurysm. A clinicomorphologic and electrocardiographic study of 80 cases. American Heart fournal, 70, 753-760.

Edwards, J. E. (1961). An Atlas of Acquired Diseases of the Heart and Great Vessels. W. B. Saunders, Philadelphia and London.

Favaloro, R. G., Effler, D., Groves, L. K., Westcott, R. N., Suarez, E., and Lozada, J. (1968). Ventricular aneurysmclinical experience. Annals of Thoracic Surgery, 6, 227-245.

Fisher, V. J., Alvarez, A. K., Shah, A., Dolgin, M., and Tice, D. A. (1974). Left ventricular scars; clinical and hemodynamic results of excision. British Heart fournal, 36, 132-138.

Graber, J. D., Oakley, C. M., Pickering, B. N., Goodwin, J. F., Raphael, M. J., and Steiner, R. E. (1972). Ventricular aneurysm. An appraisal of diagnosis and surgical treatment. British Heart fournal, 34, 830-838.

Himbert, J., and Rochemaure, J. (1967). L'anévrisme ventriculaire (In French). Coeur et Médecine Interne, 6, 3-14.

Himbert, J., Rochemaure, J., and Lenègre, J. (1966). L'électrocardiogramme dans 100 cas d'anévrismes ventriculaires autopsiés après infarctus du myocarde. Archives des Maladies $d u$ Coeur et des Vaisseaux, 59, 1389-1412.

Kitamura, S., Echevarria, M., Kay, J. H., Krohn, B. G., Redington, J. V., Mendez, A., Zubiete, P., and Dunne, E. F. (1972). Left ventricular performance before and after removal of the noncontractile area of the left ventricle and revascularisation of the myocardium. Circulation, 45, 1005-1017.

Klein, M. D., Herman, V., and Gorlin, R. (1967). A hemodynamic study of left ventricular aneurysm. Circulation, 35, 614-630.

Leaman, D. M., Gentzler, R. D., and Gault, J. H. (1973). Quantitative assessment of left ventricular performance in patients with ventricular aneurysm (abstract). Circulation, 47 and 48, Suppl. IV, 189.

Loop, F. D., Effler, F. B., Webster, J. S., and Groves, L. K. (1973). Posterior ventricular aneurysm. Etiologic factors and results of surgical treatment. Nerv England fournal of Medicine, 288, 237-239.

Mauviard, J. M. (1975). Symptomatologie, évolution et pronostic de l'infarctus du myocarde à la phase aiguë. (A propos de 200 observations.) Thesis, Faculté de Médecine de Rouen, France, p. 75. 
Mourdjinis, A., Olsen, E., Raphael, M. J., and Mounsey, J. P. D. (1968). Clinical diagnosis and prognosis of ventricular aneurysm. British Heart fournal, 30, 497-513.

Schlichter, J., Hellerstein, H. K., and Katz, L. N. (1954). Aneurysm of the heart: a correlative study of one hundred and two proved cases. Medicine, 33, 43-86.

Standiford, F. M., Reul, G. J., Dawson, J. T., Wukasch, D. C., Chiariello, L., Hallman, G. L., and Cooley, D. A. (1974). Resection of left ventricular aneurysm: report of 275 cases (abstract). American fournal of Cardiology, 33, 168.

Tice, D. A., Cheng, T. O., and Dolgin, M. (1970). Surgical treatment of post-myocardial infarction scars (ventricular aneurysms). American Heart fournal, 80, 282-286.

Watson, L. E., Dickhaus, D. W., and Martin, R. H. (1972).

The residual contracting left ventricular in patients with left ventricular anaeurysm (abstract). Circulation, 45 and 46, Suppl. II, 106.

Requests for reprints to Professor B. Letac, Charles-Nicolle, 1 rue de Germont, 76000ÎRouen, France. 